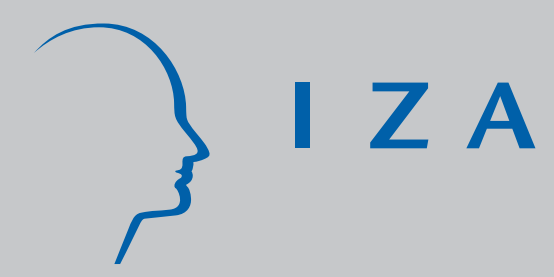

IZA DP No. 4060

Happiness and Growth the World Over:

Time Series Evidence on the Happiness-Income Paradox

Richard A. Easterlin

LauraAngelescu

March 2009 


\title{
Happiness and Growth the World Over: Time Series Evidence on the Happiness-Income Paradox
}

\author{
Richard A. Easterlin \\ University of Southern California \\ and IZA \\ Laura Angelescu \\ University of Southern California
}

Discussion Paper No. 4060

March 2009

\author{
IZA \\ P.O. Box 7240 \\ 53072 Bonn \\ Germany \\ Phone: +49-228-3894-0 \\ Fax: +49-228-3894-180 \\ E-mail: iza@iza.org
}

\begin{abstract}
Any opinions expressed here are those of the author(s) and not those of IZA. Research published in this series may include views on policy, but the institute itself takes no institutional policy positions.

The Institute for the Study of Labor (IZA) in Bonn is a local and virtual international research center and a place of communication between science, politics and business. IZA is an independent nonprofit organization supported by Deutsche Post Foundation. The center is associated with the University of Bonn and offers a stimulating research environment through its international network, workshops and conferences, data service, project support, research visits and doctoral program. IZA engages in (i) original and internationally competitive research in all fields of labor economics, (ii) development of policy concepts, and (iii) dissemination of research results and concepts to the interested public.
\end{abstract}

IZA Discussion Papers often represent preliminary work and are circulated to encourage discussion. Citation of such a paper should account for its provisional character. A revised version may be available directly from the author. 
IZA Discussion Paper No. 4060

March 2009

\section{ABSTRACT \\ Happiness and Growth the World Over: Time Series Evidence on the Happiness-Income Paradox}

There is no significant relationship between the improvement in happiness and the long term rate of growth of GDP per capita. This is true for three groups of countries analyzed separately - 17 developed, 9 developing, and 11 transition - and also for the 37 countries taken together. Time series studies reporting a positive relationship confuse a short-term positive association between the growth of happiness and income, arising from fluctuations in macroeconomic conditions, with the long-term relationship, which is nil.

JEL Classification: I31, D60, O10, P27

Keywords: happiness, economic growth, developing countries, transition countries, developed countries

Corresponding author:

Richard A. Easterlin

Department of Economics, KAP 300

University of Southern California

Los Angeles, CA 90089-0253

USA

E-mail: easterl@usc.edu 


\title{
Happiness and Growth the World Over: Time Series Evidence on the Happiness - Income Paradox
}

\author{
It's a small world after all. \\ Disney theme song
}

Simply stated, the happiness - income paradox is this: at a point in time happiness varies directly with income, but over time happiness does not increase when a country’s income increases (Easterlin 1974, 1995). The point-of-time statement is based on cross sectional comparisons of happiness and income both among and within countries; the time series statement, very largely on the experience of developed countries. This article expands the time series coverage to 37 countries -- 17 developed, 9 developing, and 11 transition. Our primary interest is factual: when the empirical scope of the time series is expanded to include not only a larger number of developed countries but transition and developing nations as well, are happiness and economic growth still unrelated? The answer suggested by the evidence is, yes.

In the last year or so the happiness - income paradox has received mixed reviews. Some analysts look rather favorably on it (Clark, Frijters, and Shields 2008; DiTella and MacCulloch 2008); others do not (Stevenson and Wolfers 2008). As will be seen, the dissenting view appears to be largely the result of failing to distinguish between the short- and long-term temporal relationship between happiness and income. Over the short term, when fluctuations in macroeconomic conditions dominate the relationship, happiness and income are positively related. Over the long term, happiness and income are unrelated. After analyzing the long term relationship, we demonstrate the short term one, and the effect of mixing the two. In the final section of this paper we speculate on the reasons for the disconnect between the short- and longterm relationship. 


\section{Concepts, Data, Methods}

Previous papers have dealt specifically with the group of transition countries (Easterlin 2009 forthcoming) and developing countries (Easterlin and Sawangfa 2009 forthcoming). An extended discussion of the data for these countries and their derivation is given in these papers. This article brings together some of the principal results of the two earlier papers, and adds an analysis of a third set of countries, the developed ones. What follows in this section is a short overview of measures, data, and methods.

Happiness is measured here by overall life satisfaction, the response to the question "All things considered, how satisfied are you with your life as a whole these days”. The principal data sources are the World Values Survey (World and European Values Surveys Four-Wave Integrated Data File 2006; World Values Survey 2005 Official Data File V.20081015, 2008), Eurobarometer (retrieved from http://zacat.gesis.org), and Latinobarometer (retrieved from http://www.latinobarometro.org). We have adjusted for survey differences in the number of response categories by rescaling to a 1-10 scale. ${ }^{1}$ Economic growth is measured in terms of the percentage growth per year in real GDP per capita. The GDP data are those of the World Bank 1975 onwards (World Development Indicators Online 2008). Those for Japan prior to 1975 are

\footnotetext{
${ }^{1}$ To rescale from a 1-4 to a 1-10 response scale, we assume a response of 4 corresponds to a response of 10, a response of 1 on the 1-4 scale to a response of 1 on the 1-10 scale, and make a linear transformation using the formula: $y=3 x-2$, where $y=$ life satisfaction on the WVS scale, and $\mathrm{x}=$ life satisfaction on the non-WVS scale. In the regression results in the analysis here the slope coefficients are those based on the rescaled responses. We date the observations on life satisfaction here, not at the actual survey dates but to match the annual GDP observations that they most likely reflect. The GDP data are for calendar years while the life satisfaction surveys typically relate to a single month or span only a few months. If a survey is conducted early in a year it would clearly be meaningless to link it to a GDP estimate covering the entire twelve months of the same year. A life satisfaction survey conducted within the first four months of a year, say, January -April 1991, is linked to 1990 GDP; a mid-year survey, conducted in the period May through August 1991 is compared to the GDP average of 1990 and 1991 and dated 1990.5; and a survey conducted in the latter part of the year, September-December 1991, is compared with 1991 GDP and dated 1991.
} 
based on a backward extrapolation of the World Bank series using the Penn World Table (Heston, Summers, and Aten 2006).

Happiness depends on many factors (Bruni and Porta 2005; Frey and Stutzer 2002;

Layard 2005a). Generalizations about growth and happiness, however, have typically been based on bivariate comparisons of national measures of happiness and per capita income; hence we too employ a bivariate methodology, with the growth rates of life satisfaction and GDP per capita the variables of interest.

We compute the long-term growth rate of life satisfaction from an OLS regression on time, taking as our period of analysis for each country the longest time span available. The longterm growth rate of GDP per capita is computed from the GDP per capita values at the start and end of the period covered by the life satisfaction observations. When more than one data set is available for a country's life satisfaction, as in the case of the Latin American countries, we compute a pooled regression with a dummy variable to identify the different data set. Growth rates for both life satisfaction and GDP are per year; the change in life satisfaction is measured in absolute terms on a 1-10 scale; that in GDP per capita, in percentage terms.

In our analysis of long-term rates of change the minimum time span for any country is 12 years. In taking long periods for analysis the purpose is specifically to distinguish the longer from the shorter term relationship between life satisfaction and GDP per capita, although even 12 years may be too short a period (Easterlin and Sawangfa 2009). For most countries the period actually spanned is usually longer, as can be seen from the following:

\begin{tabular}{lcc} 
& \multicolumn{2}{c}{ Time span } \\
\cline { 2 - 3 } 17 developed countries & Mean & Range \\
11 transition countries & 29 & $21-34$ \\
9 developing countries & 15 & $12-22$ \\
& 19 & $15-33$
\end{tabular}


The small number of transition and developing countries relative to developed is because of the limited happiness data available.

Both the life satisfaction and GDP data are imperfect. We note briefly here the principal problems with the less-familiar life satisfaction data and what we have done to improve comparability over time. (For a full discussion see Easterlin and Sawangfa 2009, http://wwwrcf.usc.edu/ easterl/papers/Happiness_and_Growth_Appendix.pdf).

First, the question on life satisfaction may change over time, as in the case of Japan (see Stevenson and Wolfers 2008, Table 5 for a valuable digest of the Japanese data) ${ }^{2}$. For such cases, we pool the data and use dummy variables for the different segments to account for the difference in response level attributable to the change in survey questions.

Second, the context of the life satisfaction question may change. In the Eurobarometer, for example, there are a few surveys in which a question on satisfaction with finances is inserted before that on overall life satisfaction. People generally are less satisfied with their finances than with life in general, and the replacement of a neutral question with one on financial satisfaction tends to bias downward responses on life satisfaction. We have deleted the life satisfaction observations in the years that are so biased. ${ }^{3}$

Third, the geographic coverage of the surveys may change over time, especially for the developing countries. We try to minimize the effects of such shifts by constructing series that cover the same population at different dates. Typically the coverage is for at least 70 per cent of the population and comprises the more literate and urbanized segment of the population, those

\footnotetext{
2 Japan's GDP per capita in 1958 was 11 per cent of the 2000 value for the United States, putting it well within the developing category. The time span analyzed here for Japan is 1958 - 1991. By the latter date Japan had risen to 80 per cent of the 2000 U.S. value. We omit the ensuing period of economic stagnation in Japan.

${ }^{3}$ The following surveys were biased due to the financial satisfaction question: October - November 1985, 1986, 1987, and 1990. We also deleted the survey conducted in November - December 2004 due to a different question format.
} 
most likely to be experiencing the income benefits of economic growth. Also, for two countries, China and South Africa, there are independent surveys by other organizations that provide support for the time series change indicated by the series we use.

We make no claim that the time series analyzed here are faultless. We have, however, done our best to make the series for the various countries reasonably comparable over time.

\section{Results}

\section{The Cross Sectional Relationship}

We start with a point-of-time comparison of happiness and income in richer and poorer countries. The contradiction between this cross sectional relationship and the time series one is the essence of the happiness - income paradox, but curiously -- as will be seen below -- the cross sectional relationship is frequently cited as though it disproves the time series evidence.

Two main conclusions emerge from the cross sectional analysis:

1. If richer and poorer countries are compared at a point in time, life satisfaction increases with the absolute amount of GDP per capita, but at a diminishing rate (Figure 1). This cross sectional relationship has led some analysts to assert that increases in GDP per capita have a much bigger impact on happiness in poorer than richer countries. Here, for example, are two typical statements by scholars who have made pioneering contributions to the economics of happiness:

Comparing across countries, it is true that income and happiness are positively related and that the marginal utility falls with higher income. Higher income clearly raises happiness in developing countries, while the effect is only small, if it exists at all, in rich countries (Frey and Stutzer 2002, p. 90). 
[E]conomic growth is indeed more important for poor than for rich countries - as the diminishing marginal utility of income would lead us to expect (Layard 2005b, p. 150).

One imagines that it is statements like these that lead to assertions such as the following in the thoughtful volume on the discipline of economics by Diane Coyle (2007, p. 188): “There is no doubt that the vast majority of people in the world will be made happier by increases in GDP per capita”.

2. If richer and poorer countries are compared at a point in time, "[e]ach doubling of GDP is associated with a constant increase in life satisfaction” (Deaton 2008, p. 57, Fig. 2). This generalization is illustrated here in Figure 2 using exactly the same regression relationship as that underlying Figure 1, but now the change in life satisfaction is measured in relation to the proportionate, rather than absolute change in GDP, and life satisfaction is plotted against log GDP, not absolute GDP. The implication for change over time is more sweeping than for the first generalization. Now economic growth raises life satisfaction in rich as well as poor countries and to the same extent. Moreover, the higher the rate of economic growth, the greater the improvement in life satisfaction -- doubling the rate at which GDP per capita grows doubles the improvement in happiness.

The direct quotation at the start of the paragraph above, attributable to Angus Deaton, is based on data different from those used here, 2006 Gallup World Poll data for 132 countries. As aptly illustrated in other work (Cutler, Deaton, and Lleras-Muney 2006) Deaton himself is well aware that cross sectional relationships may be a poor guide to historical experience. But others are less cautious. Thus, Derek Bok in a valuable forthcoming book on The Politics of Happiness cites Deaton's statement as contradicting time series evidence on the absence of relationship 
between happiness and economic growth. Similarly, Daniel Kahneman's (2008) mea culpa on the hedonic treadmill is based on a cross sectional relationship found in the Gallup World Poll (Kahneman 2008).

Time Series Evidence: Long Series

In turning to time series, our point of departure is the implication of Figure 2 that a greater increment in happiness goes with a higher rate of economic growth. Here is what we find:

1. For 17 developed countries with time series ranging from 21 to 34 years, there is no significant relationship between the rate of improvement in life satisfaction and the growth rate of GDP per capita (Figure 3). The countries here are most of the developed countries of Europe plus the United States, Canada, and Australia. For most countries the long term GDP growth rates are between 1.5 and 3 per cent, but for two, Ireland and Luxembourg, the rates are between 3 and 5 per cent. If Ireland and Luxembourg are deleted, there is still no significant relationship, as can readily be seen from a glance at Figure 3 .

2. For 9 developing countries with time series ranging from 15 to 33 years, there is no significant relationship between the rate of improvement in happiness and the rate of economic growth (Figure 4). The nine countries are typically fairly populous, four in Asia, four in Latin America, and one in sub-Saharan Africa. The economic growth rates range from around zero for South Africa to almost 10 per cent per year for China. If China, the outlier in the group, is omitted, the regression coefficient remains not significant.

3. For 11 transition countries with time series ranging from 12 to 22 years, there is no significant relationship between the improvement in life satisfaction and the rate of economic 
growth (Figure 5). The eleven countries are those for which there is a life satisfaction observation near the start of the transition (cf. Easterlin 2009 forthcoming), and range across central and eastern Europe. Their economic growth rates are from slightly negative to about 3 per cent per year.

4. For all 37 countries taken together, with time series ranging from 12 to 34 years in length, there is no significant relation between the improvement in life satisfaction and the rate of economic growth (Figure 6). The growth rates of GDP per capita typically range from slightly negative to almost 6 per cent. If the one outlier, China at almost 10 per cent, is omitted, the regression coefficient is still not significant.

\section{Time Series Evidence: Short Series}

Over the short term life satisfaction and GDP per capita are positively related, moving together with macroeconomic conditions. This was first pointed out with regard to the experience of the developed countries by DiTella, MacCulloch, and Oswald (2001). It is most readily apparent visually in simple time series plots for the transition countries, where the collapse and recovery of GDP per capita has often been on a scale much like that of the 1930s Great Depression (Figure 7). For some transition countries, such as Slovenia, the first life satisfaction observation comes rather late in the transition and, as a result, only the recovery phase of the life satisfaction movement is observed (Figure 8), leading some analysts mistakenly to confuse the short-term positive association of life satisfaction and GDP per capita with the long term trend relationship. Clearly, inferences about the long term trend need to be based on time series that capture both the collapse and recovery phases of the transition. This is what we have tried to do for the eleven transition countries analyzed in the preceding section. Even for these countries, 
however, whose initial life satisfaction observation is around 1990, the time series may not go back far enough, for there is fragmentary evidence for a few transition countries that in the 1980s life satisfaction may have been higher than around 1990 (Easterlin 2009 forthcoming).

In any event, it is clear that taking contraction periods and expansion periods separately, with a mean time span of 7.6 years, one observes a significant positive relationship between the improvement in life satisfaction and the rate of economic growth (Figure 9). Now the GDP growth rates range from very large negative rates, approaching -20 per cent, to large positive rates, close to 10 per cent, and the coefficient of the regression line fitted to these data is significantly positive. In the short run a negative change in GDP per capita is associated with a negative change in life satisfaction and the recovery of GDP per capita is associated with a recovery of life satisfaction.

\section{Time Series Evidence: Mixing Short and Long Series}

Over the long term there appears to be no significant relation between the improvement in happiness and the growth rate of GDP per capita; in the short run, however, the two are positively associated. If short and long series are mixed together, the short term positive relationship tends to dominate. This is most simply demonstrated by returning to the long-term series for 37 countries in Figure 6 and replacing the long-term time trends for the eleven transition countries with the data for the contraction and expansion periods separately, used in Figure 9. Not surprisingly, the short-term observations dominate the long-term, and the coefficient of the regression line fitted to the data is significantly positive (Figure 10). The longterm economic growth rates are mainly clustered between zero and 5 per cent, while the shortterm rates range more widely and shape the slope of the regression line. 
An example of the failure to distinguish the short term from the long term relationship is the widely-publicized Stevenson and Wolfers (2008) paper that seeks to establish a positive relation between life satisfaction and economic growth. In their time series analysis of World Values Survey data they estimate regression relationships like those done here between the change in life satisfaction and that in GDP per capita. They report the results of three "short first differences" and three "long first differences” regressions after eliminating countries whose data they consider noncomparable over time (Stevenson and Wolfers 2008, Figure 15). The time spans of the "short first differences" regressions - typically five to six years - are too brief to identify the long-term relationship between life satisfaction and GDP per capita. Of their three "long first differences" regressions only two have a significant positive coefficient. The significant positive coefficient for the waves II to IV regression (based on observations for 32 countries) is due to the inclusion of eleven transition countries, whose data particularly reflect the concurrent collapse and recovery of life satisfaction and GDP per capita in these countries. If the transition countries are omitted from the regression, the slope coefficient is no longer significant. ${ }^{4}$ The significant positive coefficient for the waves I to IV analysis, based on seventeen countries, is due to the inclusion of one transition country, Hungary, with low growth in GDP per capita and a negative change in life satisfaction, and one developing country, South Korea, with very high growth in GDP per capita (it is off-scale in their diagram) and high growth of life satisfaction. Among the other 15 countries, all of which are developed, there is no significant relation between the change in life satisfaction and that in GDP per capita. Thus, the positive association between the change in life satisfaction and that in GDP per capita reported

\footnotetext{
${ }^{4}$ In re-doing the Stevenson and Wolfers' analysis we have converted both variables to a per year basis, because the interval between two given waves sometimes differs among countries. The effect on the results is negligible.
} 
by Stevenson and Wolfers rests almost entirely on the short-term association between happiness and GDP per capita, particularly in the transition countries.

Our discussion of the shorter term happiness-income relation has been based on evidence from the transition countries, where the positive association is readily apparent in simple time series graphs. However, even some of the non-transition countries exhibit the short-term relationship in raw data. For example, we do not include in our long series analysis of the developed countries, data for Austria, Sweden, and Finland. The Eurobarometer surveys for these countries begin quite late, in the 1990s. In all three of these countries unemployment rates in the 1990s were much worse than the long-term average; by 2006, however, unemployment rates had substantially improved in Finland and Sweden, producing a positively related recovery in life satisfaction and GDP per capita like that observed in the transition countries.

\section{Why Do the Short and Long Term Relationships between Happiness and Economic Growth Differ?}

A definitive answer to this question is beyond the scope of the present analysis. But a speculative answer is this: what one is observing in the disjunction between short and long-term relationships is the counterpart of the phenomenon of "loss aversion" reported in the literature of social psychology and behavioral economics. A considerable number of small group studies have found that an increase in income from an initial reference point means considerably less to people in terms of well-being than a loss of equivalent amount (the pioneering study is Tversky and Kahneman 1991; see also Rabin 1998, Kahneman 2003). The relevance of this argument here can be illustrated by adapting a figure from Easterlin (2001). 
Assume that at a given point in time, mean income is $\mathrm{y}_{1}$ and happiness $\mathrm{u}_{1}$ on the utility function $A_{1}$, which illustrates the cross sectional positive relation observed between happiness and income (Figure 11). If when income increases, aspirations rise commensurately, then when GDP per capita increases from $\mathrm{y}_{1}$ to $\mathrm{y}_{2}$, average happiness remains unchanged at $\mathrm{u}_{1}$ (a movement from point 1 to point 2, illustrated by the heavy broken line connecting the two points). This is because the positive effect on happiness of the growth in GDP per capita (an upward movement along $A_{1}$ ) is undercut by a downward shift in the utility function from $A_{1}$ to $A_{2}$ as rising material aspirations shrink the happiness value of a given dollar of income. If, however, GDP per capita falls, say from $\mathrm{y}_{1}$ to $\mathrm{y}_{3}$, and income aspirations remain fixed at their initial level, then happiness falls from $\mathrm{u}_{1}$ to $\mathrm{u}_{2}$ (a downward movement along $\mathrm{A}_{1}$ from point 1 to point 3 , illustrated by the broken line connecting these points). Correspondingly, a recovery in GDP per capita from $\mathrm{y}_{3}$ that moves people back along $A_{1}$ toward the reference level, point 1 , raises happiness back toward $\mathrm{u}_{1}$. For illustrative purposes the diagram pictures the extreme case of complete hedonic adaptation to an income gain, and zero adaptation to an income loss.

Put simply, the argument is that people adapt hedonically to an increase in income from a given initial level, their aspirations tending to rise commensurately with income. But aspirations are much less flexible downward. Once people have attained a given level of income, they cling to this reference point -- the well-known "endowment effect” (Kahneman, Knetsch, and Thaler 1991). Hence, if income falls they feel deprived, and their subjective well-being declines. In turn, a recovery in income that returns them toward the reference level increases subjective wellbeing. Readers will note that the kink in the broken line at point 1 of Figure 2 is analogous to that in diagrams of loss aversion (Kahneman, Knetsch, and Thaler, p. 200). The movement between 
points 1 and 2 illustrates the long term happiness - income relationship; that between points 1 and 3, the short term relationship.

\section{Conclusion}

The happiness - income paradox is the contradiction between the cross sectional relation of happiness and income (positive) and the time series relation (nil). The present time series analysis of the long term relationship between the improvement in happiness and the rate of economic growth reveals no significant relationship in three groups of countries considered separately -- 17 developed, 9 developing, and 11 transition -- or when all three sets of countries are taken together.

Rejection of the paradox is based usually on two grounds. The most frequent case is where the first part of the paradox, the cross section relationship, is cited as disproving the second, the time series relationship. This is, to say the least, a puzzling bit of logic. More pertinent are recent time series findings at variance with the asserted absence of the happiness income relationship. In the present analysis we demonstrate that these conflicting results arise chiefly from confusing a short-term positive happiness - income association, due to fluctuations in macroeconomic conditions, with the long-term relationship. We suggest, speculatively, that this disparity between the short and long-term association is due to the social psychological phenomenon of "loss aversion".

When we started this analysis a couple of years ago we had no preconceptions as to the empirical findings; with happiness data newly becoming available for many more countries in the world, we were curious to see what the data might reveal about long term trends. To us, as to many others, it is disquieting to find no relationship between happiness and economic growth 
even in poorer countries. The aspiration mechanism described above may provide part of the explanation; certainly no evidence has been advanced indicating that lower income countries are immune to this mechanism. Perhaps also changes in noneconomic domains of life satisfaction, such as family, social capital, and the environment, are offsetting the effect of gains in the economic domain.

It is conceivable too that as better happiness data become available for longer time spans, a significant (though perhaps slight) positive long-term relation between happiness and growth will emerge. Nevertheless, the fact that the surveys now available fail to pick up a positive happiness - income association in countries exhibiting such a wide disparity in economic growth rates is remarkable. Consider, for example, three countries included here with very high recent growth rates of GDP per capita -- China, Chile, and South Korea. China's growth rate implies a doubling of real income in less than 10 years; South Korea's, in 13 years; and Chile's in 18 years. With the per capita amount of goods multiplying so rapidly in a fraction of a lifetime, one might think many of the people in these countries would be so happy they'd be dancing in the streets. Yet both China and Chile show mild (not statistically significant) declines in life satisfaction - China in surveys conducted by three different statistical organizations. South Korea - none of whose surveys has been faulted - shows a (not statistically significant) increase, but all of the increase results from the low value reported in the initial survey, one that was conducted a few months after the assassination of the country's president in 1980. Thereafter, in four surveys from 1990 to 2005, a period when GDP per capita continued to grow rapidly, averaging 5 percent per year, life satisfaction declines slightly. With incomes increasing so greatly in three different countries it seems extraordinary that there are no surveys that register the marked improvement in subjective well-being that one might expect to find. 
One can easily imagine reasons for dismissing the present results: "The data are no good" (although to the best of our abilities we have tried to screen and test the data for comparability over time). "If perceptions (i.e., reports of happiness) and objective measures of well-being (GDP per capita) differ -- well, we all know that perceptions can be faulty” (but, faulty or not, this is what people feel, and what they act on).

Alternatively, we might consider whether the data are trying to tell us something -perhaps that the casual assumption that economic growth is a sure route to greater well-being requires re-examination. Maybe there is need for broader and deeper research into the myriad ways other than the accumulation of goods that economic growth affects people's lives.

\section{Acknowledgements}

We are grateful for helpful comments to Andrew Oswald, Mariano Rojas, Onnicha Sawangfa, and Jacqueline Smith. Happiness data for Norway were kindly provided by Ottar Hellevik. For guidance on Northern Ireland GDP we are grateful to José L.I. D’Elia and Victor Hewitt. Financial support was provided by the University of Southern California. 
Figure 1

Diminishing Marginal Utility of Income

[Life Satisfaction and GDP per Capita (Absolute Scale) Based on WVS Cross Section ( $n=195)$ ]

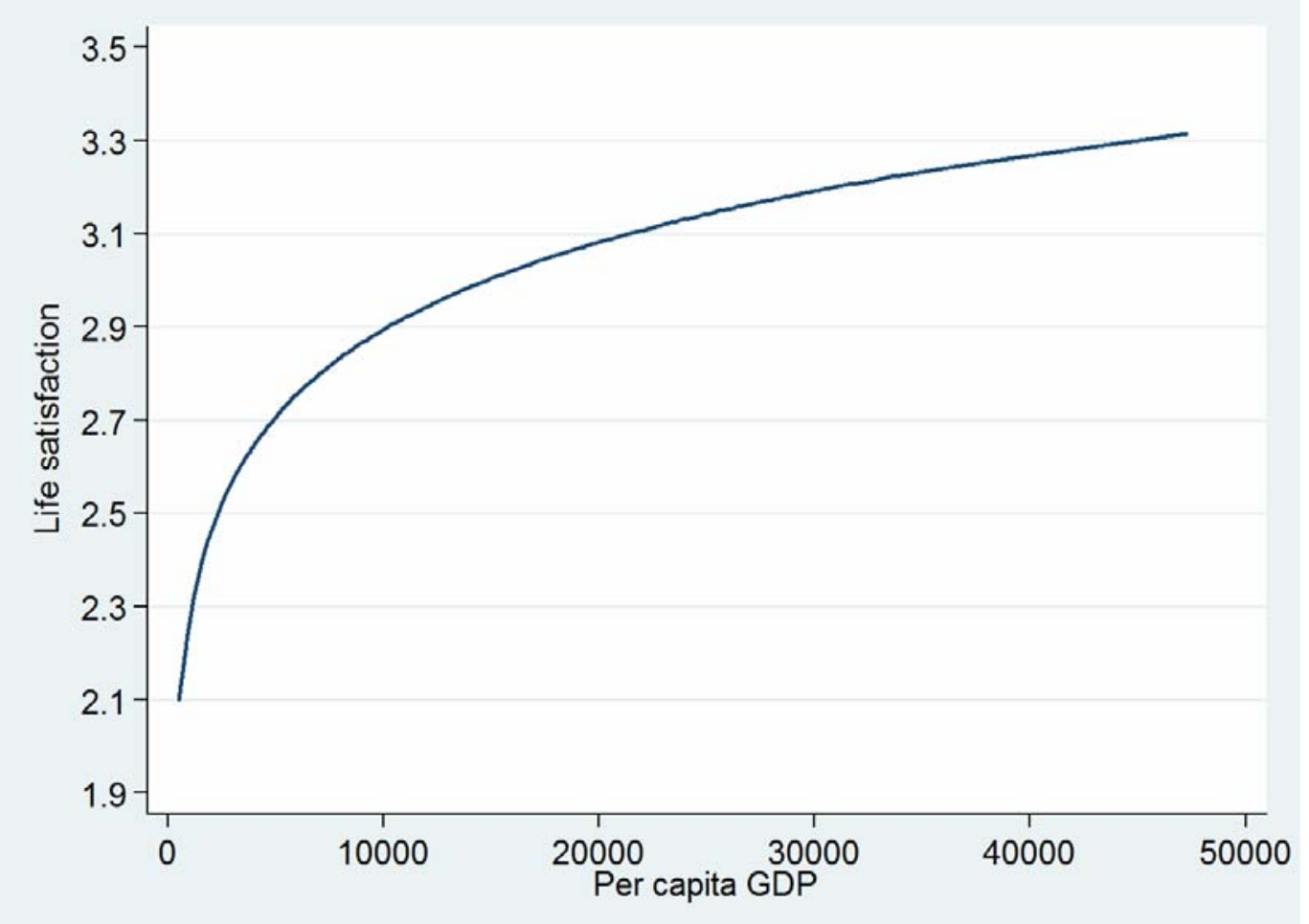

Source: The basic data are 195 pooled observations for 89 countries surveyed in waves 1-4 of the World Values Survey. Individual country observations are omitted from the figure. The fitted regression is $\mathrm{y}=0.405+0.270 \ln (\mathrm{x})$ (adjusted $\left.\mathrm{R}^{2}=0.452\right)$; t-statistics in parentheses. 
Figure 2

"Each Doubling of GDP is Associated with a Constant Increase in Life Satisfaction" [Life Satisfaction and GDP per Capita (Logarithmic Scale) Based on WVS Cross Section $(n=195)]$

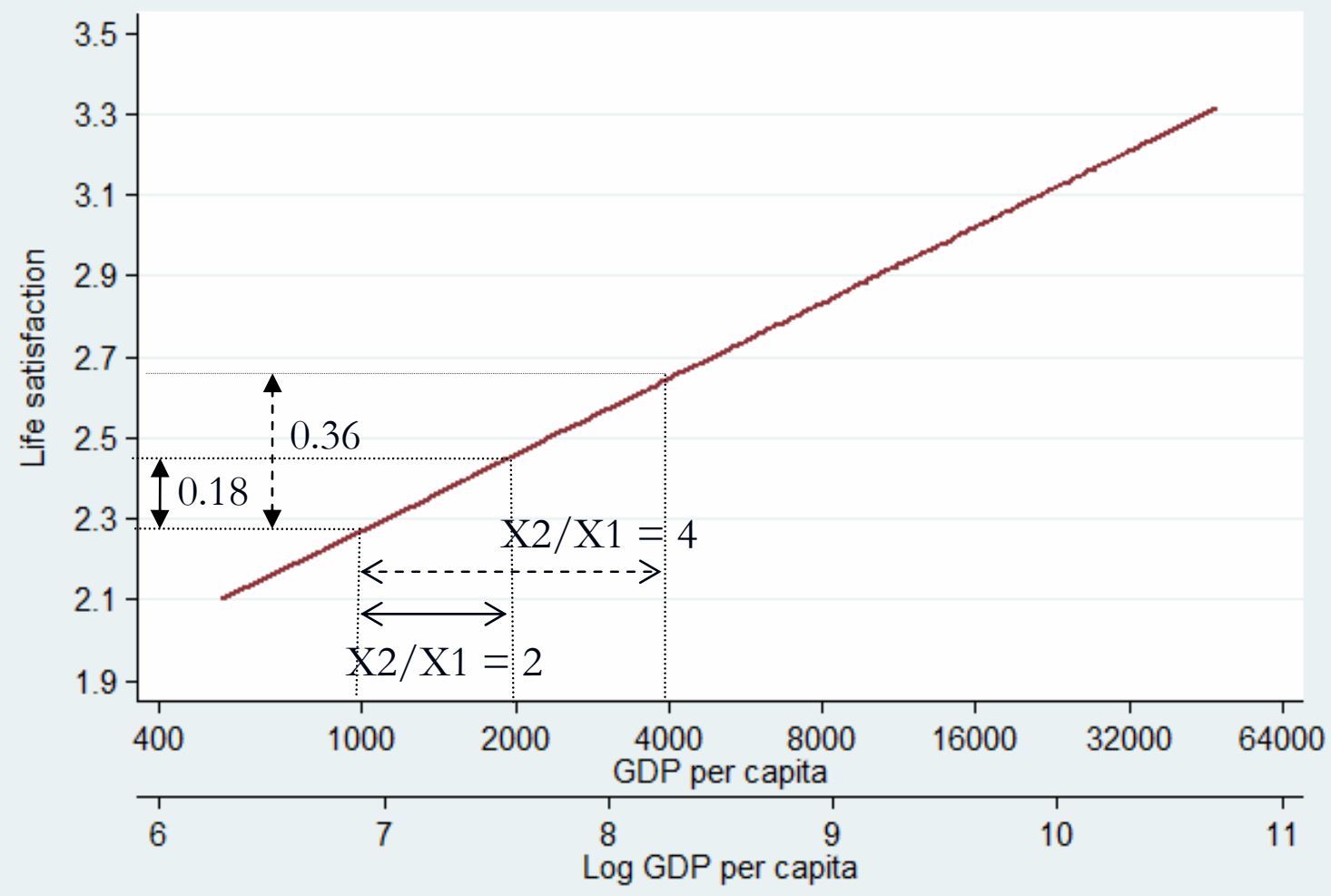

Source: See Fig. 1. 
Figure 3

Longer Term Relationship between Growth Rates of Life Satisfaction and GDP per Capita: 17 Developed Countries (21-34 Years; Mean=29)

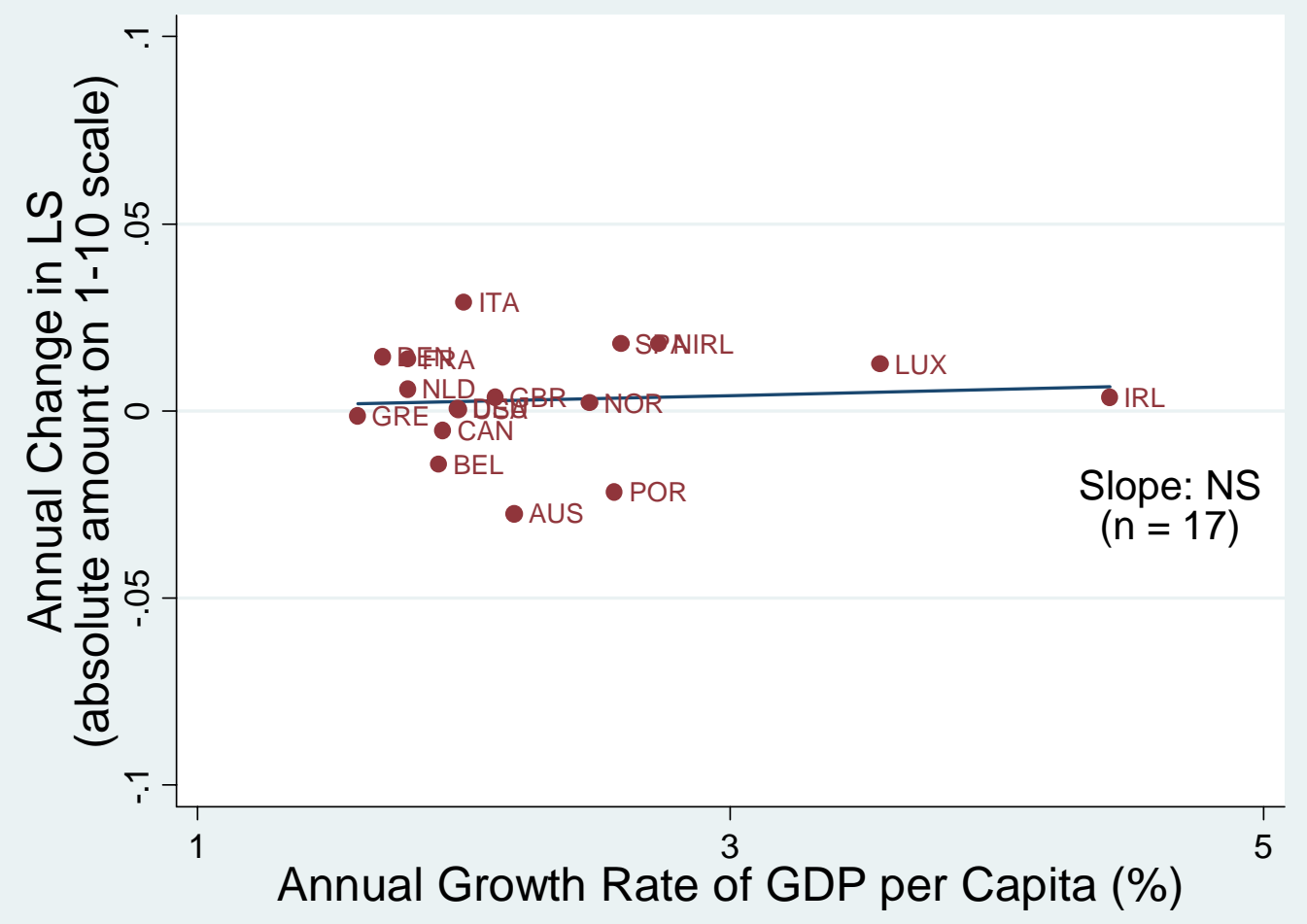

Source: See text. The fitted regression is $\mathrm{y}=-0.001+0.002 \mathrm{x}$ (adjusted $\left.\mathrm{R}^{2}=0.006\right)$; t-statistics in parentheses. $(-0.05) \quad(0.31)$ 
Figure 4

Longer Term Relationship between Growth Rates of Life Satisfaction and GDP per Capita: 9 Developing Countries (15-33 Years; Mean=19)

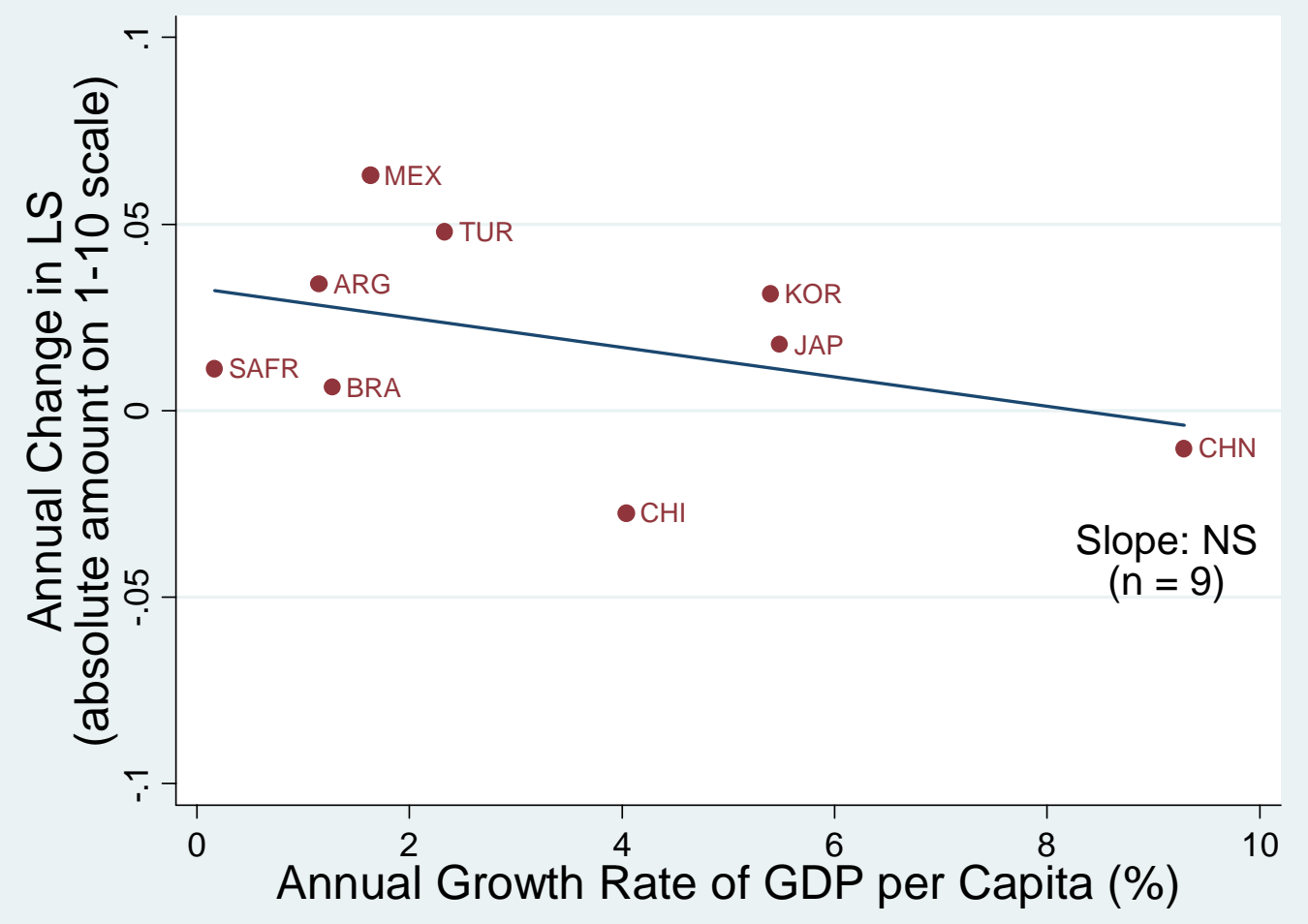

Source: See text. The fitted regression is $\mathrm{y}=0.033-0.004 \mathrm{x}$ (adjusted $\left.\mathrm{R}^{2}=0.168\right)$; $\mathrm{t}$-statistics in parentheses. (2.24) (-1.19) 
Figure 5

Longer Term Relationship between Growth Rates of Life Satisfaction and GDP per Capita: 11 Transition Countries (12-22 Years; Mean=15)

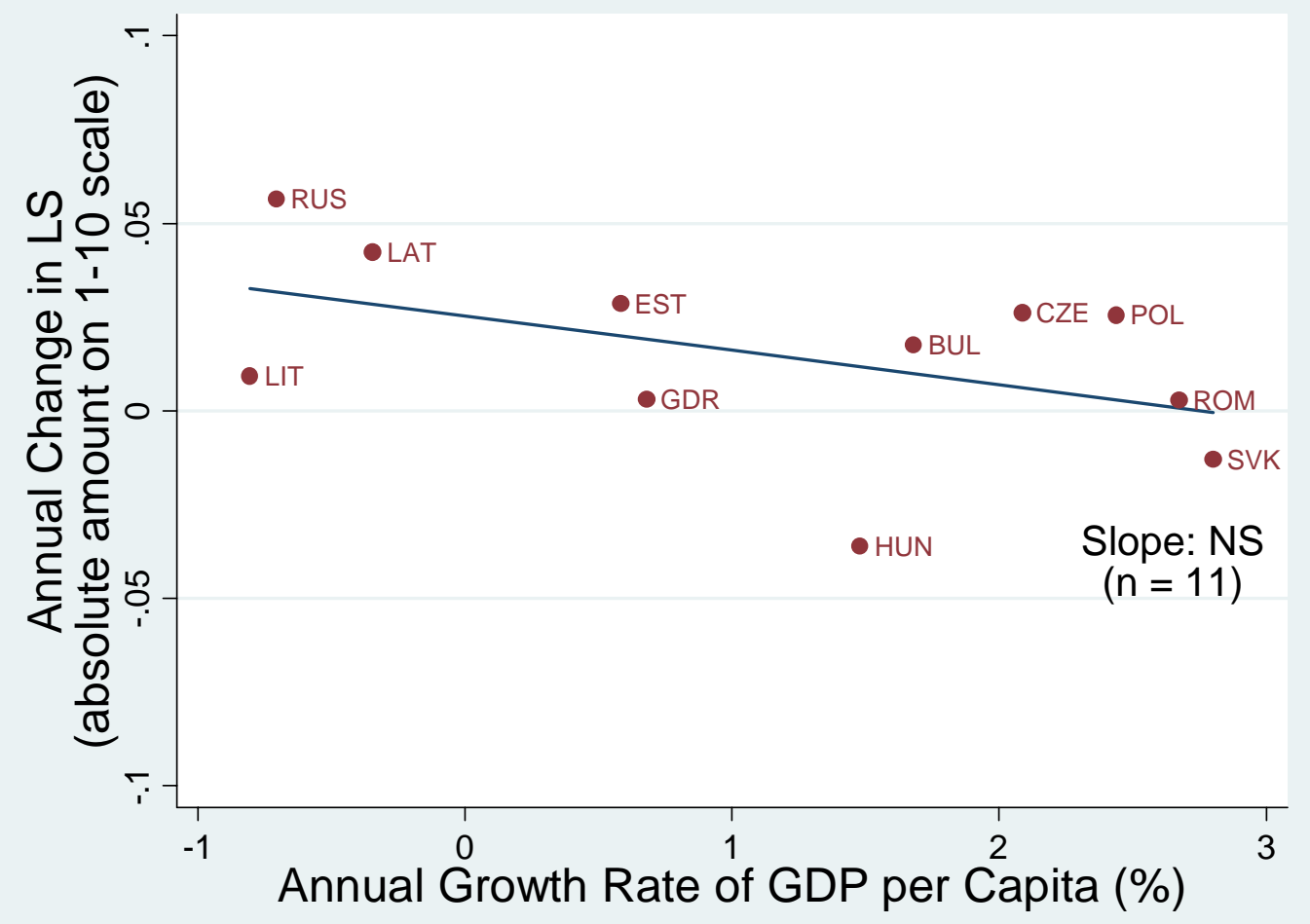

Source: See text. The fitted regression is $\mathrm{y}=0.025-0.009 \mathrm{x}$ (adjusted $\left.\mathrm{R}^{2}=0.229\right)$; $\mathrm{t}$-statistics in parentheses. (2.62) (-1.63) 
Figure 6

Longer Term Relationship between Growth Rates of Life Satisfaction and GDP per Capita: 17 Developed, 11 Transition, and 9 Developing Countries (12-34 Years; Mean=22)

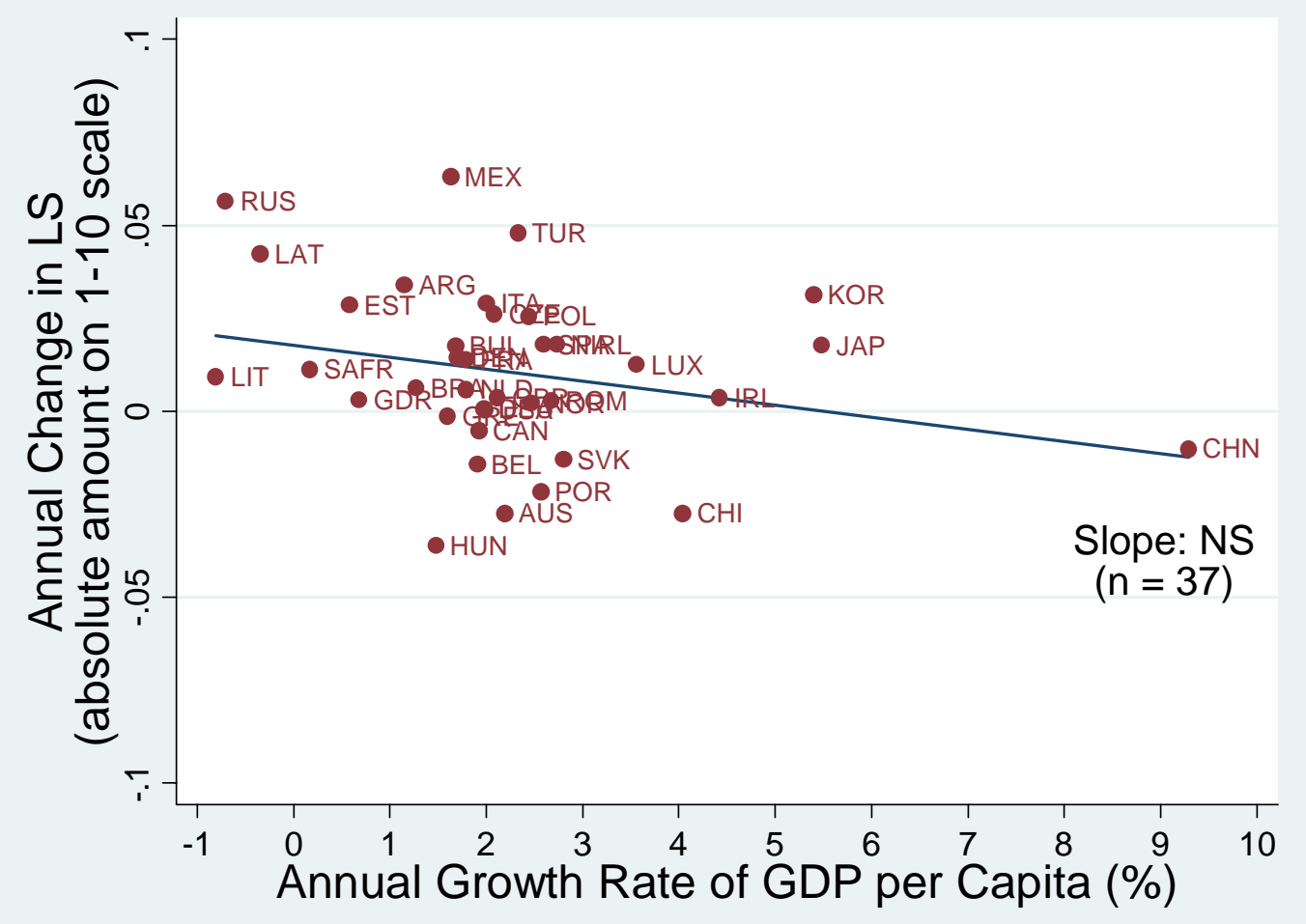

Source: See text. The fitted regression is $\mathrm{y}=0.018-0.003 \mathrm{x}$ (adjusted $\left.\mathrm{R}^{2}=0.069\right)$; $\mathrm{t}$-statistics in parentheses. (3.07) (-1.61) 


\section{Figure 7}

Life Satisfaction, c. 1990 - 2005, and Index of Real GDP: Three Transition Countries
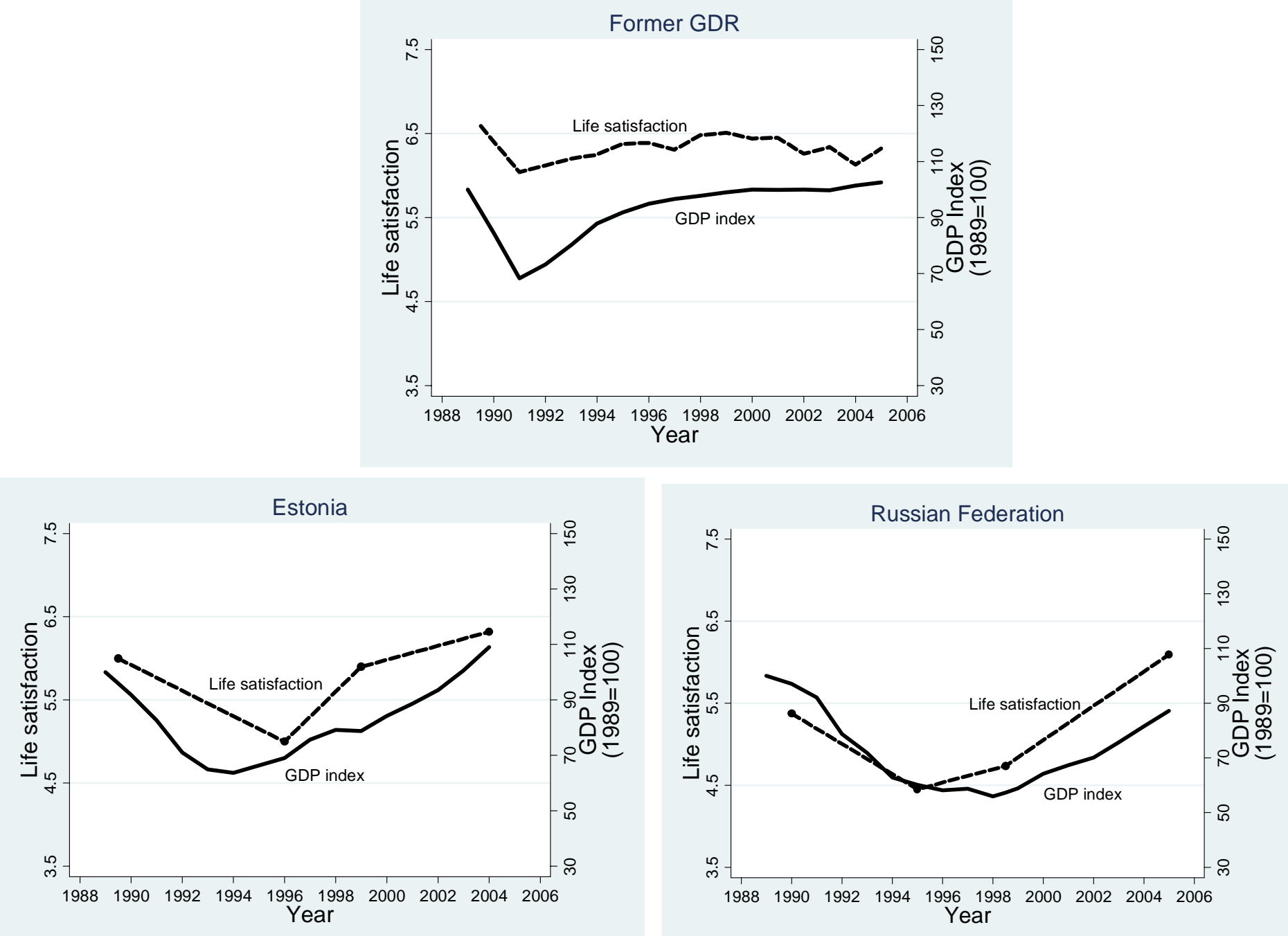

Source: Easterlin (2009 forthcoming). 
Figure 8

Life Satisfaction, 1992-2005, and GDP per Capita, 1989 - 2005: Slovenia
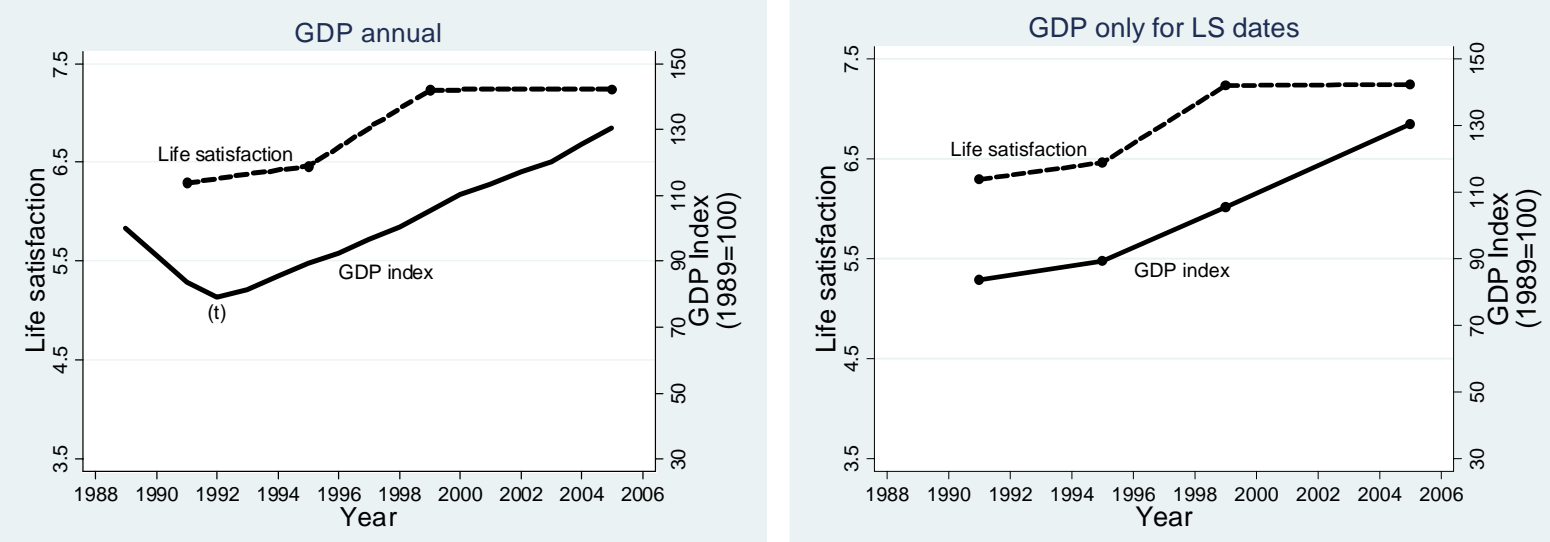
Figure 9

Short Term Relationship between Growth Rates of Life Satisfaction and GDP per Capita: 11 Transition Countries - Contraction and Expansion Periods Separately (Mean=7.6 Years)

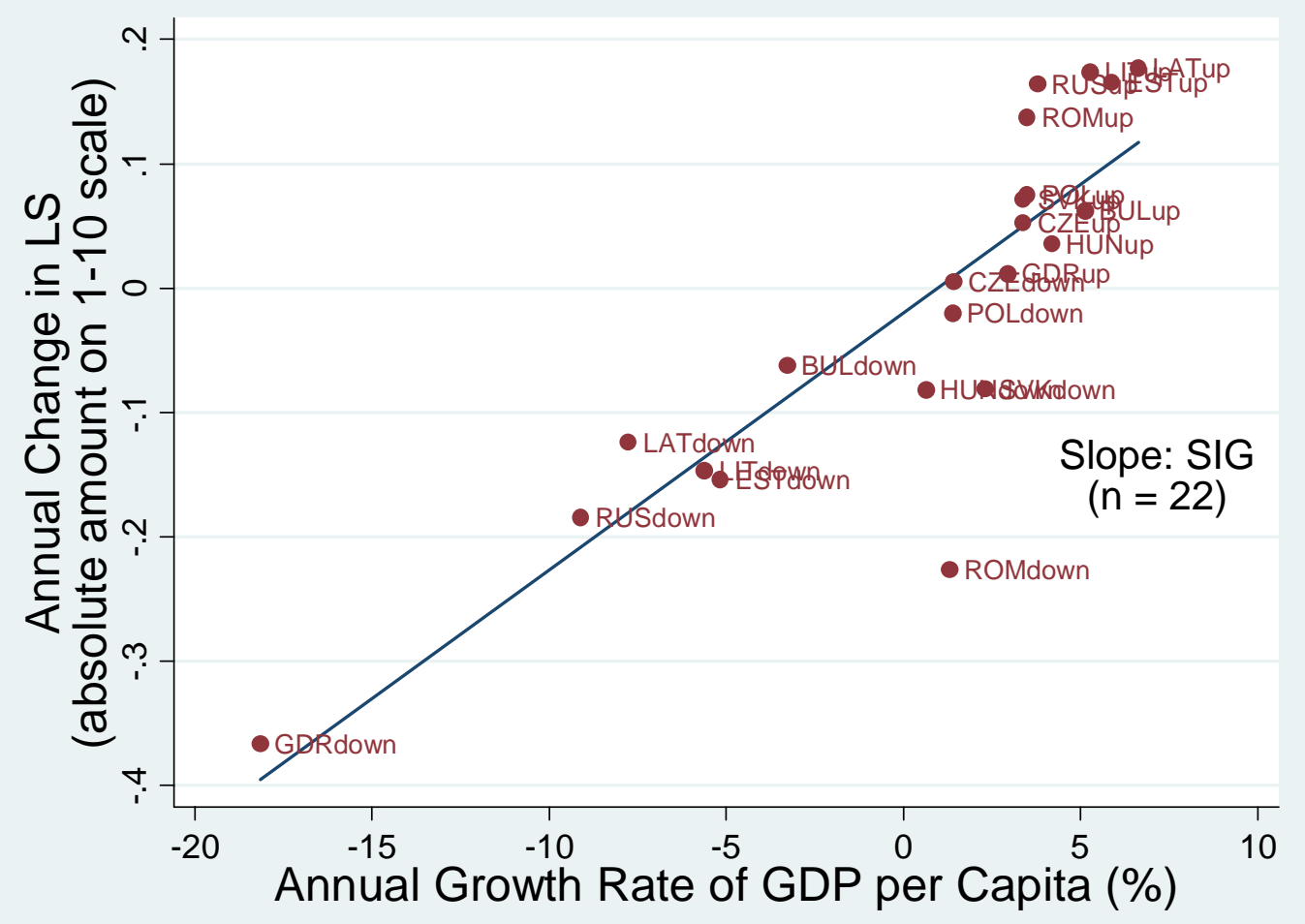

Source: See text. The fitted regression is $\mathrm{y}=-0.020+0.021 \mathrm{x}$ (adjusted $\mathrm{R}^{2}=0.741$ ); t-statistics in parentheses.

$(-1.22) \quad(7.57)$ 
Figure 10

Mixing the Long and Short Term Relationship between Growth Rates of Life Satisfaction and GDP per Capita: 11 Transition Countries -- Contraction and Expansion Periods Separately -- plus 17 Developed and 9 Developing Countries

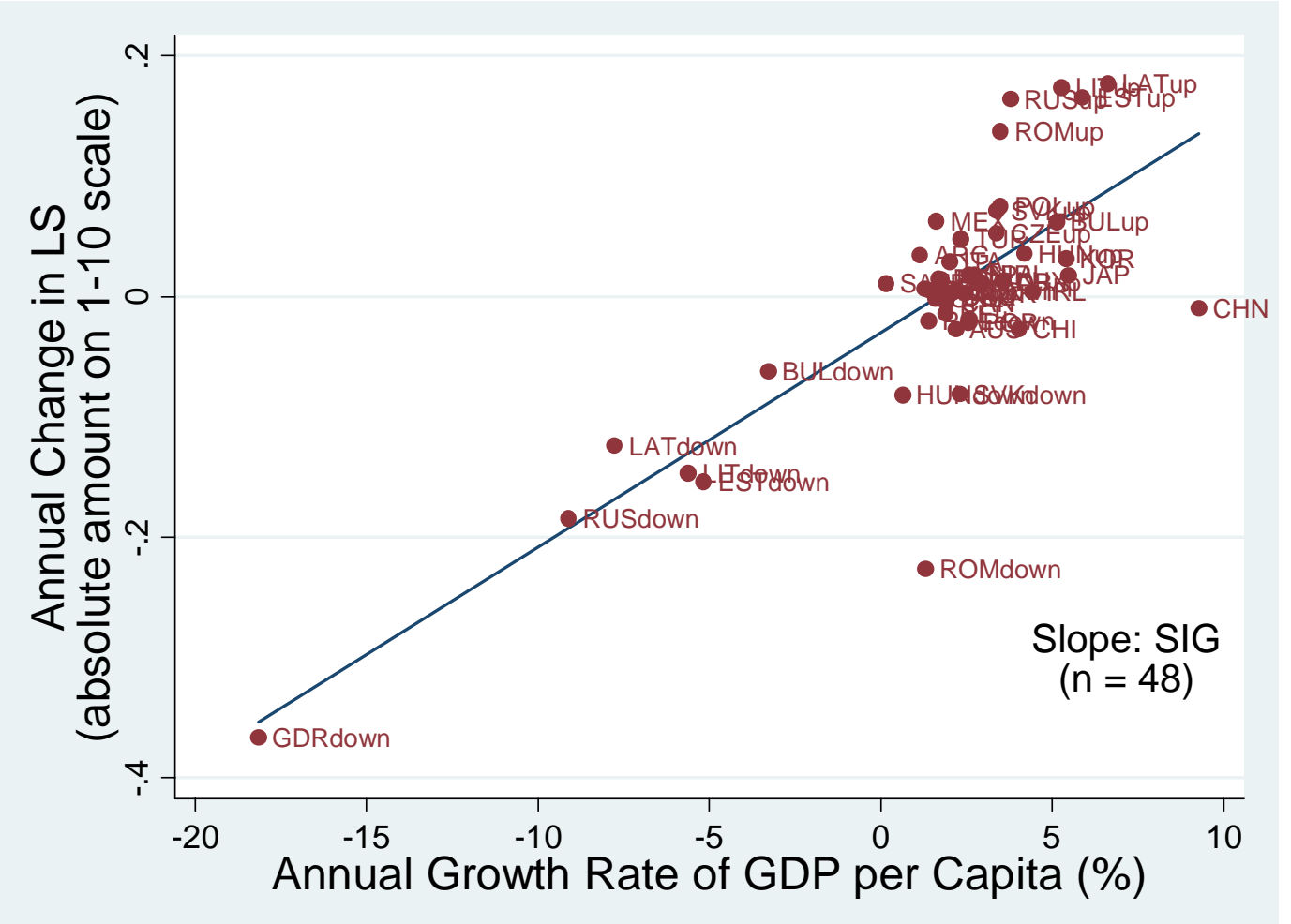

Source: See text. The fitted regression is $\mathrm{y}=-0.030+0.018 \mathrm{x}$ (adjusted $\mathrm{R}^{2}=0.634$ ); $\mathrm{t}$-statistics in parentheses. $(-3.22) \quad(8.92)$ 
Figure 11

Subjective Well-being (u) as a Function of Income (y) and Aspiration Level (A)

Subjective well-being

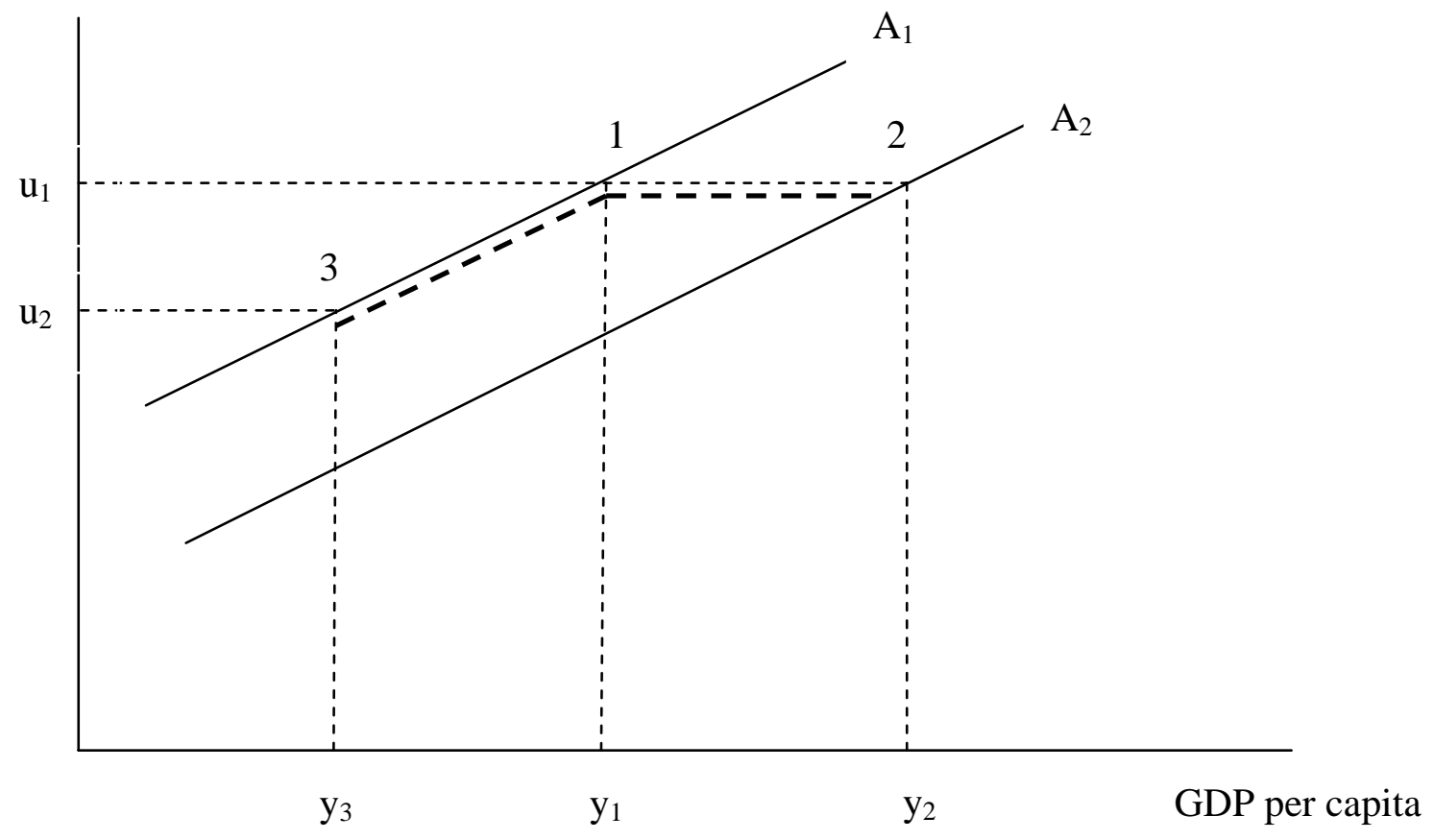




\section{References}

Bruni, Luigino, and Pier L. Porta. 2005. Economics and Happiness: Framing the Analysis. Oxford, UK: Oxford University Press.

Clark, Andrew E., Paul Frijters, and Michael A. Shields. 2008. "Relative Income, Happiness, and Utility: An Explanation for the Easterlin Paradox and Other Puzzles.” Journal of Economic Literature. 46(1): 95-144.

Coyle, Diane. 2007. The Soulful Science. Princeton:Princeton University Press.

Cutler, David, Angus Deaton, and Adriana Lleras-Muney. 2006. “The Determinants of Mortality.” Journal of Economic Perspectives, 20(3): 97-120.

Deaton, Angus. 2008. "Income, Health, and Well-Being around the World: Evidence from the Gallup World Poll.” Journal of Economic Perspectives, 22(2): 53-72.

Di Tella, Rafael, Robert MacCulloch, and Andrew J. Oswald. 2001. "Preferences over Inflation and Unemployment: Evidence from Surveys of Happiness.” American Economic Review, 91(1): 335-341.

DiTella, Rafael, and Robert MacCulloch. 2008. "Gross national happiness as an answer to the Easterlin Paradox?” Journal of Development Economics, 86(1): 22-42.

Easterlin, Richard A.. 1974. "Does Economic Growth Improve the Human Lot?” In Nations and Households in Economic Growth: Essays in Honor of Moses Abramovitz, eds. Paul A. David and Melvin W. Reder. New York: Academic Press.

Easterlin, Richard A.. 1995. "Will Raising the Incomes of All Increase the Happiness of All?” Journal of Economic Behavior and Organization, 27(1): 35-48.

Easterlin, Richard A.. 2001. "Income and Happiness: Towards a Unified Theory.” The Economic Journal, 111(473): 465-484.

Easterlin, Richard A. forthcoming 2009. "Lost in Transition: Life Satisfaction on the Road to Capitalism.” Journal of Economic Behavior and Organization. An earlier version appeared as IZA Discussion Paper 3409.

Easterlin, Richard A. and Onnicha Sawangfa. Forthcoming 2009. "Happiness and Growth: Does the Cross Section Predict Time Trends? Evidence from Developing Countries.” In International Differences in Wellbeing, eds. Ed Diener, John Helliwell, and Daniel Kahneman. Princeton: Princeton University Press.

Frey, Bruno S., and Alois Stutzer. 2002. Happiness and Economics: How The Economy and Institutions Affect Well-Being. Princeton, NJ: Princeton University Press.

Heston, Alan, Robert Summers, and Bettina Aten. 2006. Penn World Table Version 6.2. Center for International Comparisons of Production, Income and Prices, University of Pennsylvania. (URL: http://pwt.econ.upenn.edu/php_site/pwt_index.php accessed on February 14, 2008)

Kahneman, Daniel, Jack L. Knetsch, and Richard H. Thaler. 1991. “Anomalies: The Endowment Effect, Loss Aversion, and Status Quo Bias.” Journal of Economic Perspectives, 5(1): 193-206.

Kahneman, Daniel. 2003. “A Psychological Perspective on Economics.” American Economic Association Papers and Proceedings, 93(2): 162-168.

Kahneman, Daniel. 2008. The sad tale of the aspiration treadmill. Edge World Question Center at http://www.edge.org/q2008/q08_17.html\#kahneman.

Layard, Richard. 2005a. Happiness: Lessons from a New Science. New York: Penguin Press. 
Layard, Richard. 2005b. "Rethinking Public Economics: The Implications of Rivalry and Habit.” In Economics and Happiness: Framing the Analysis, eds. Luigino Bruni and Pier Luigi Porta, 147-169. New York: Oxford University Press.

Rabin, Matthew. 1998. "Psychology and Economics.” Journal of Economic Literature, 36(1): 11-46.

Stevenson, Betsey, and Justin Wolfers. 2008. "Economic Growth and Subjective WellBeing: Reassessing the Easterlin Paradox.” IZA Discussion Paper 3654, Institute for the Study of Labor.

Tversky, Amos, and Daniel Kahneman. 1991. "Loss Aversion in Riskless Choice: A Reference-Dependent Model.” Quarterly Journal of Economics, 106(4): 1039-61.

World and European Values Surveys Four Wave Integrated File, 1981-2004, v.20060423. 2006. World Value Survey Association (www.worldvaluessurvey.org) and European Values Study Foundation (www.europeanvalues.nl).

World Development Indicators. World Bank. Retrieved from February 26, 2008 to June 11, 2008 from http://go.worldbank.org/IW6ZUUHUZ0.

World Values Survey 2005 Official Data File, v.20081015. 2008. World Values Survey Association (www.worldvaluessurvey.org). Aggregate File Producer: ASEP/JDS, Madrid. 